\title{
Design, Synthesis, Crystal Structure and Photophysical Properties of New Oxadiazole Extended Viologen Fluorophore
}

\author{
Tetsuji Moriguchi ${ }^{1 *}$, Masataka Okuyama1, Venkataprasad Jalli2 ${ }^{2}$ \\ ${ }^{1}$ Department of Applied Chemistry, Faculty of Engineering, Kyushu Institute of Technology, 1-1 Sensui-cho, Tobata-ku, \\ Kitakyushu, Japan \\ ${ }^{2}$ Sankar Foundation, Research and Development Division, Visakhapatnam, Andhra Pradesh, India \\ Email: *moriguch@che.kyutech.ac.jp
}

How to cite this paper: Moriguchi, T., Okuyama, M. and Jalli, V. (2021) Design, Synthesis, Crystal Structure and Photophysical Properties of New Oxadiazole Extended Viologen Fluorophore. Crystal Structure Theory and Applications, 10, 27-37. https://doi.org/10.4236/csta.2021.102003

Received: February 10, 2021

Accepted: March 2, 2021

Published: March 5, 2021

Copyright $\odot 2021$ by author(s) and Scientific Research Publishing Inc. This work is licensed under the Creative Commons Attribution International License (CC BY 4.0).

http://creativecommons.org/licenses/by/4.0/

(c) (i) Open Access

\begin{abstract}
Viologens ( $N, N^{\prime}$-dimethyl-4,4-bipyridinium) are advanced functional materials, found important applications in electrochromic devices, molecular machines, organic batteries, and carbohydrate oxidation catalysts in alkaline fuel. In this article, we investigated the design, synthesis and photophysical properties of $N, N^{\prime}$-dimethyl-2,5-Bis(pyridinium)oxadiazole 4 and its precursor 2,5Bis(pyridine)oxadiazole 2 . The crystal structure and photophysical properties of viologen 4 and precursor 2 have been determined. The viologen molecule 4 crystallized in monoclinic form, space group $P 2_{1} / n$ with four molecules in unit cell. Precursor molecule 2 also crystalized in monoclinic form, space group $C 2 / c$ with four molecules in unit cell. From X-rd data, we found three cations in the molecular structure of viologen molecule 4 , which is unusual in viologens. In the three-dimensional molecular packing diagram of molecule 4 , the three cations and iodate anions are stabilized by $\mathrm{C} \cdots \mathrm{C}, \mathrm{C} \cdots \mathrm{I}, \mathrm{N} \cdots \mathrm{I}, \mathrm{N} \cdots \mathrm{H}, \mathrm{H} \cdots \mathrm{I}$, $\mathrm{N}-\mathrm{H} \cdots \mathrm{I}$ and $\mathrm{C}-\mathrm{H} \cdots \mathrm{I}$. The dihedral angle between planes having oxadiazole and two benzene rings are $5^{\circ}$ and $8^{\circ}$, suggesting the molecule 4 is a slightly strained one. The molecular structure of precursor molecule 2 stabilized by $\mathrm{C} \cdots \mathrm{C}$ and $\mathrm{N} \cdots \mathrm{H}$ short contacts between the molecules. The molecule 4 displayed strong absorbance at $315 \mathrm{~nm}$ and emissions between $390-410 \mathrm{~nm}$.
\end{abstract}

\section{Keywords}

Oxadiazole Extended Methyl Viologen, Bipyridine Oxadiazole, Crystal Structure, Pyridine-4-Carboxy Aldehyde, Isonicotinic Acid Hydrazide, Fluorescence

\section{Introduction}

1,1-Dialkyl-4,4-bipyridinium salts are commonly known as viologens. Undoub- 
tedly, viologens are the advanced functional materials, which have been studied extensively in the past decade. A number of reviews and research articles have been published on viologens in the past decade [1] [2] [3] [4] [5]. Due to the important properties of viologens such as ionic conductivity, redox properties, photochromism, elctrochromism and thermochromism, they have been used in electrochromic devices, molecular machines, organic batteries, and carbohydrate oxidation catalysts in alkaline fuel [6] [7] [8] [9] [10]. They have also been used as herbicides, ionic liquids and ionic liquid crystals by substituting different alkyl chains or new groups between the pyridinium rings [11] [12] [13].

Among the various viologens reported, viologens with extended $\pi$-conjugation are of great interest in photochromic devices because of the readable physical photoswitching properties of these materials. In this category, thiazolothiazole, diphenyl extended viologen fluorophore resulted in strong fluorescence with photo switchable optical properties [14] [15] [16]. Considering the vast number of applications of viologens, it is important to analyze the crystal structures of viologens to assess the important information about charge transfer interaction, distance between the electron donor and acceptor, packing of cations and anions in the molecule and its effect on fluorescence, photoswitching properties. Very few studies have been reported on the X-ray diffraction analysis of these molecules [17] [18] [19] [20]. Herein, we report the synthesis, crystal structure and photophysical properties of $N, N^{\prime}$-dimethyl-2,5-Bis(pyridinium)oxadiazole 4 and its precursor 2,5-Bis(pyridine)oxadiazole 2. We believe that this study helps in designing new viologens with desired property of interest.

\section{Experimental}

\subsection{Materials and Methods}

Reagent grade pyridine-4-carboxyaldehyde, isonicotinic acid hydrazide, methyl iodide and TFA were purchased from the TCI chemicals industry, Tokyo and used as such. The ${ }^{1} \mathrm{H}$-NMR spectra were recorded on a Bruker AVANCE400S spectrometer (Bruker, Yokohama, Japan) in DMSO- $\mathrm{d}^{6}, \mathrm{CDCl}_{3}$ or $\mathrm{D}_{2} \mathrm{O}$ with tetramethyl silane $\left(\mathrm{Me}_{4} \mathrm{Si}\right)$ deuterated 3-(Trimethylsilyl)-1-propanesulfonic acid sodium salt $\left(D S S-\mathrm{d}^{6}\right)$ as an internal reference, respectively. SHIMADZU UV1850 (Shimadzu Corporation, Kyoto, Japan) was used for obtaining UV-Vis spectra in dichloromethane with 250 - $900 \mathrm{~nm}$ range. HITACHI F-2500 spectrophotometer (Hitachi High-Technologies Corporation, Tokyo, Japan) was used for fluorescence spectra measurements in dichloromethane with $250-900 \mathrm{~nm}$ range. CCDC No. 1945691 and 2058072 contain the supplementary crystallographic data for the viologen molecule 4 and its precursor molecule 2 , respectively.

\subsection{General Procedure for the Synthesis of Viologen Molecule 4 and Its Precursor 2}

\section{Preparation of intermediate 1}

To a methanol solution of isonicotinic acid hydrazide ( $2.00 \mathrm{~g}, 14.6 \mathrm{mmol}), \mathrm{Py}-$ 
ridine-4-carboxaldehyde $(1.78 \mathrm{ml}, 14.6 \mathrm{mmol})$ in $200 \mathrm{ml}$ methanol, and catalytic amount of TFA were added and the reaction mixture was stirred for $3 \mathrm{hrs}$ at room temperature. The solvent methanol was removed from the reaction mixture under reduced pressure, and then, resulting pale yellow precipitates were collected by filtration. The precipitates were washed with hexane and dried under reduced pressure. The collected product was purified by recrystallization using ethanol to give desired intermediate 1 as white solid, Yield $2.60 \mathrm{~g}, 78.8 \%$.

Mp. $241^{\circ} \mathrm{C}-243^{\circ} \mathrm{C},{ }^{1} \mathrm{H}-\mathrm{NMR}\left(\left(\mathrm{CD}_{3}\right)_{2} \mathrm{SO}\right): 7.67-7.69(2 \mathrm{H}, \mathrm{Ar}-\mathrm{H}), 7.81-7.83$ $(2 \mathrm{H}, \mathrm{Ar}-\mathrm{H}), 8.44(1 \mathrm{H}, \mathrm{Ar}-\mathrm{CH}=\mathrm{NR}), 8.65-8.67(2 \mathrm{H}, \mathrm{Ar}-\mathrm{H}), 8.78-8.80(2 \mathrm{H}$, Ar-H).

\section{Preparation of 2,5-Bis(pyridine)oxadiazole 2}

To a solution of Isoniazid imine intermediate $(1.00 \mathrm{~g}, 4.42 \mathrm{mmol})$ in $100 \mathrm{ml}$ of 1:1 DCM and DMF, PIFA (2.09 g, $4.86 \mathrm{mmol}$ ) was added slowly, and stirred for $3 \mathrm{hrs}$ at room temperature. The reaction mixture was poured into water. The organic layer was washed with saturated $\mathrm{NaHCO}_{3}$ aqueous solution, dried over $\mathrm{MgSO}_{4}$. The solvent DCM was removed from the reaction mixture under reduced pressure. The resulting product was washed with hexane to give desired cyclisation Intermediate $2(0.611 \mathrm{~g}, 61.6 \%)$.

Mp. $191^{\circ} \mathrm{C}-193^{\circ} \mathrm{C},{ }^{1} \mathrm{H}-\mathrm{NMR}\left(\mathrm{CDCl}_{3}\right): 8.01$ - $8.03(4 \mathrm{H}, \mathrm{Ar}-\mathrm{H}), 8.88$ - $8.90(4 \mathrm{H}$, Ar-H).

\section{Preparation of intermediate 3}

The cyclisation intermediate $2(0.506 \mathrm{~g}, 2.22 \mathrm{mmol})$ was dissolved in iodomethane $(10.0 \mathrm{ml}, 0.161 \mathrm{~mol}$, excess), and the reaction mixture was stirred for $1 \mathrm{hrs}$ at room temperature. The resulting precipitate was collected by filtration, dried under reduced pressure to give the orange monomethylated Intermediate 3 $(0.787 \mathrm{~g}, 95.2 \%)$.

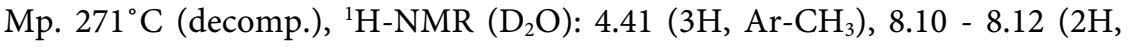
Ar-H), 8.63 - 8.75 (2H, Ar-H), 8.75 - 8.77 (2H, Ar-H), 8.98 - 9.00 (2H, Ar-H).

\section{Preparation of $N, N^{\prime}$-dimethyl-2,5-Bis(pyridinium)oxadiazole 4}

The monomethylated molecule $(0.505 \mathrm{~g}, 1.78 \mathrm{mmol})$ was dissolved in $100 \mathrm{ml}$ of DMF, iodomethane $(20.0 \mathrm{ml}, 0.321 \mathrm{~mol}$, excess) was added drop wise to the solution, and the reaction mixture was stirred for $2 \mathrm{hrs}$ at room temperature. The resulting precipitates were collected by filtration, dried under reduced pressure to give the desired orange product $(0.578 \mathrm{~g}, 82.5 \%)$.

Mp. $285^{\circ} \mathrm{C}$ (sublimation), ${ }^{1} \mathrm{H}-\mathrm{NMR}\left(\mathrm{D}_{2} \mathrm{O}\right): 4.42\left(6 \mathrm{H}, \mathrm{Ar}-\mathrm{CH}_{3}\right), 8.67-8.69(4 \mathrm{H}$, Ar-H), 9.02 - 9.04 (4H, Ar-H).

\subsection{Single-Crystal X-Ray Analysis and Structure Determination}

Single crystals of oxadiazole extended viologen molecule 4 and its precursor 3 were obtained from a solution of benzene/ethanol at room temperature using slow diffusion method. The single crystal X-ray data were collected on a Bruker APEX II KY diffractometer equipped with graphite monochromatized (doubly curved silicon crystal) Mo-K $\alpha$-radiation $(\lambda=0.71073 \AA$ ) from a sealed micro 
focus tube, and a nominal crystal to area detector distance of $59 \mathrm{~mm}$. Generator settings were $50 \mathrm{kV}, 30 \mathrm{~mA}$. Data collection temperature was $90-120 \mathrm{~K}$. Data were acquired using three sets of omega scans at different Phi settings. The frame width was $0.5^{\circ}$. The crystallographic data of oxadiazole extended viologen molecule 4 and its precursor 2 were summarized in Table 1. APEX2 software was used for preliminary determination of the unit cell [21]. Determination of integrated intensities and unit cell refinement were performed using SAINT program [22]. The structures were solved with SHELXS-2014/7 [23] and subsequent structure refinements were performed with SHELXL-2014/7.

\section{Results and Discussion}

Reaction Scheme 1 for the synthesis of precursor 2 and oxadiazole extended Table 1. Crystallographic data for the complexes (2 and $\mathbf{4})$.

\begin{tabular}{|c|c|c|}
\hline Parameters measured & 2 & 4 \\
\hline Empirical formula & $\mathrm{C}_{12} \mathrm{H}_{8} \mathrm{~N}_{4} \mathrm{O}$ & $\mathrm{C}_{14} \mathrm{H}_{14} \mathrm{~N}_{4} \mathrm{O}, \mathrm{C}_{2} \mathrm{H}_{8} \mathrm{~N}, \mathrm{I}_{3}$ \\
\hline Formula weight & 224.22 & 681.08 \\
\hline Crystal shape, color & Prism, colorless & Prism, colorless \\
\hline Temperature & $90 \mathrm{~K}$ & $120 \mathrm{~K}$ \\
\hline Radiation type & Mo Ka & Mo Ka \\
\hline Wavelength $(\AA)$ & 0.71073 & 0.71073 \\
\hline Crystal system & Monoclinic & Monoclinic \\
\hline Space group & $C 2 / c$ & $P 2_{1} / n$ \\
\hline \multirow{4}{*}{ Unit cell dimensions } & $\mathrm{a}=5.2346(5) \AA$ & $\mathrm{a}=10.5616(10) \AA$ \\
\hline & $\mathrm{b}=12.0314(11) \AA$ & $\mathrm{b}=11.9639(11) \AA$ \\
\hline & $c=16.4648(15) \AA$ & $c=18.0399(17) \AA$ \\
\hline & $\beta=92.126(1)^{\circ}$ & $\beta=94.052(1)^{\circ}$ \\
\hline Cell volume & $1036.23(17) \AA^{3}$ & $2273.7(4) \AA^{3}$ \\
\hline $\mathrm{Z}$ & 4 & 4 \\
\hline Calculated density & $1.437 \mathrm{~g} / \mathrm{cm}^{3}$ & $1.99 \mathrm{~g} / \mathrm{cm}^{3}$ \\
\hline Absorption coefficient & $0.098 \mathrm{~mm}^{-1}$ & $4.137 \mathrm{~mm}^{-1}$ \\
\hline $\mathrm{F}(000)$ & 464 & 1280 \\
\hline Crystal size $(\mathrm{mm})$ & $0.30 \times 0.30 \times 0.20$ & $0.40 \times 0.30 \times 0.20$ \\
\hline $\mathrm{T}$ Theta range for data collection & $2.51^{\circ}$ to $28.5^{\circ}$ & $2.04^{\circ}$ to $25.05^{\circ}$ \\
\hline \multirow{3}{*}{ Limiting Indices } & $-7 \leq h \leq 6$ & $-12 \leq h \leq 12$ \\
\hline & $-16 \leq k \leq 15$ & $-14 \leq k \leq 14$ \\
\hline & $-22 \leq 1 \leq 21$ & $-21 \leq 1 \leq 21$ \\
\hline Reflections & $1333 / 5951$ & $21,235 / 4019$ \\
\hline collected/unique & {$[\mathrm{R}(\mathrm{int})=0.017]$} & {$[\mathrm{R}(\mathrm{int})=0.021]$} \\
\hline Completeness to theta ${ }^{\circ}$ & $99.90 \%$ & $99.90 \%$ \\
\hline
\end{tabular}


viologen molecule 4 is shown below. Pyridine-4-carboxyaldehyde on condensation with isonicotinic acid hydrazide gave the intermediate 1, which on treatment with PIFA gave the precursor 2. Precursor 2 on treatment with methyl iodide in two successive steps yielded the oxadiazole extended viologen 4.

Further, we measured the UV-vis absorptions and fluorescence emissions of the viologen molecule 4. The UV-vis absorptions and Fluorescence emissions of the viologen molecule 4 measured in dichloromethane solution $\left(1.0 \times 10^{-4} \mathrm{~mol} / \mathrm{L}\right)$, and their corresponding spectra is shown in Figure 1. The viologen molecule 4 showed strong absorption maximum at $315 \mathrm{~nm}$.

The fluorescence spectra of the viologen molecule 4 was recorded in dichloromethane solution $\left(1.0 \times 10^{-4} \mathrm{~mol} / \mathrm{L}\right)$, and their emission spectra is shown in Figure 2. Fluorescence Emission spectrum of the molecule was measured by exciting the viologen molecule 4 at their absorption maximum wavelength $315 \mathrm{~nm}$. The fluorescence spectra of viologen molecule 4 displayed sharp peaks in the

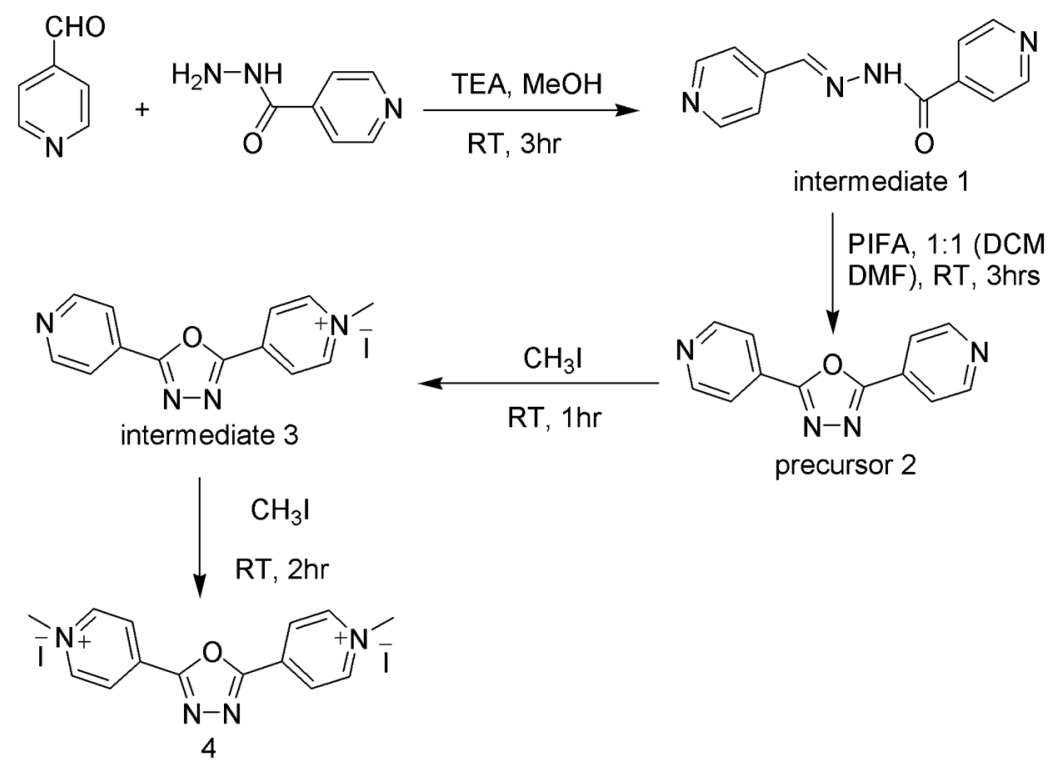

Scheme 1. Reaction scheme for the synthesis of precursor 2 and oxadiazole extended viologen 4 .

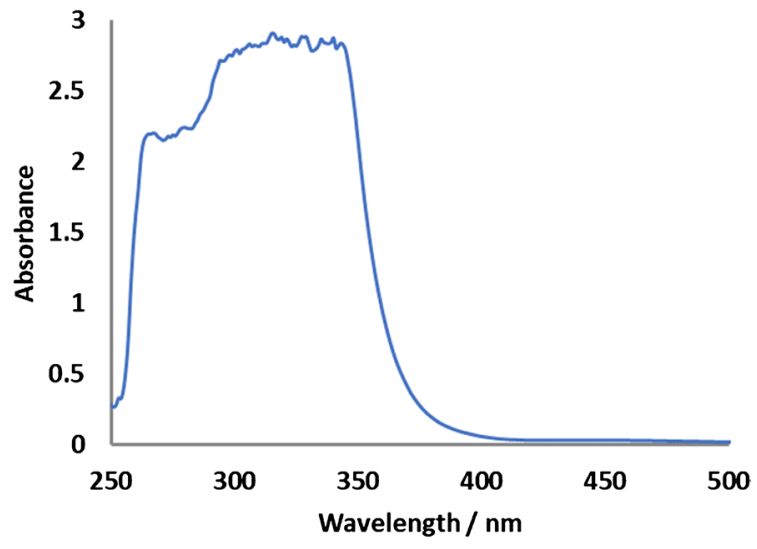

Figure 1. UV-Vis spectra of viologen molecule 4. 


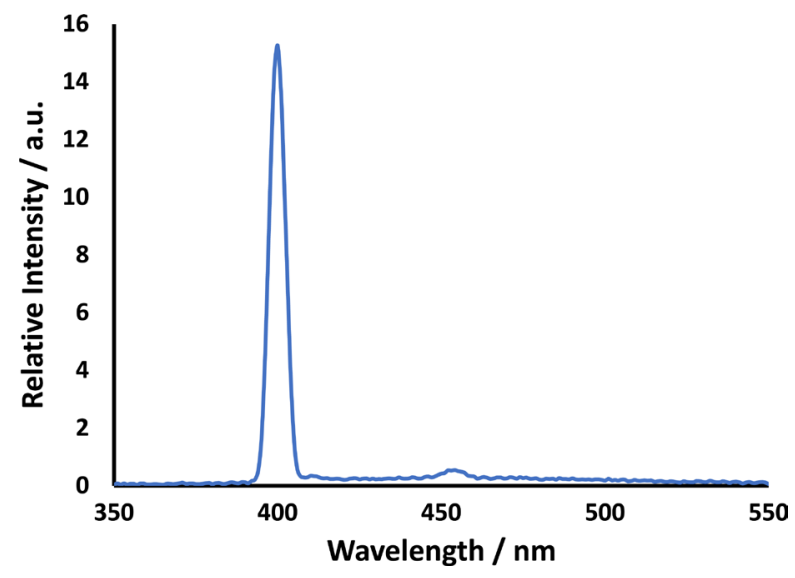

Figure 2. Fluorescence spectra of viologen molecule 4 .

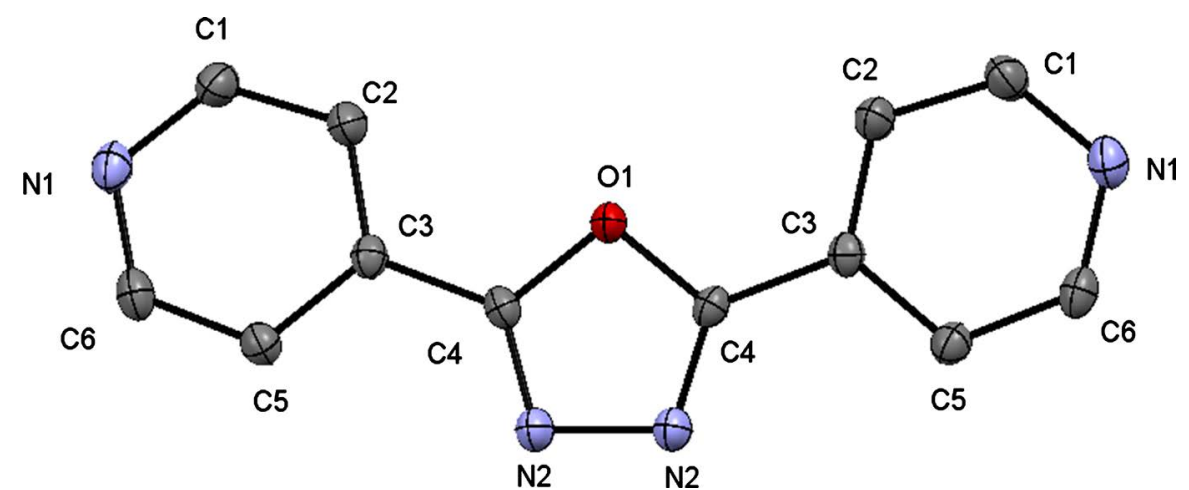

Figure 3. Molecular structure of precursor 2. Thernal ellipsoids are drawn on 50\% probability level. Hydrogen atoms are omitted for clarity.

region $390-410 \mathrm{~nm}$.

The crystallographic data of precursor molecule 2 and viologen molecule 4 summarized in Table 1 . The precursor 2 has the molecular formula $\mathrm{C}_{12} \mathrm{H}_{8} \mathrm{~N}_{4} \mathrm{O}$, contains one-half of the formula unit. The molecular structure of precursor 2 has a monoclinic form, space group $P 2_{1} / n$ with four molecules in unit cell. The molecular structure of precursor 2 is shown in Figure 3. It appears to be planar, but it is not a perfect planar molecule. The angel between the planes of pyridine (defined by C1, C2, C3, C5, C6, N1) and oxadiazole (defined by O1, C4, C4, N2, $\mathrm{N} 2)$ is $3.78^{\circ}$. This suggests that the two heteroaromatic rings are not perfect planar, the molecule has a slightly distorted structure.

Crystal packing diagram of precursor 2 is shown in Figure 4 and intermolecular short contact is shown in Figure 5. In the crystal, the molecules are stabilized by $\mathrm{C} \cdots \mathrm{C}$ and $\mathrm{N} \cdots \mathrm{H}$ short contacts between the molecules. The intermolecular short contact of precursor 2 is shown in Table 2 .

From the crystallographic data, it was concluded that molecule $\mathbf{4}$ crystallizes with monoclinic crystal system, space group $P 2_{1} / n$ with four non-planar molecules in the unit cell. Figure 6 shows the Ortep diagram of molecule 4. In general, viologen molecules are dicationic molecules. To our surprise, X-ray data indicated that presence of three cations in the structures with three iodate counter 


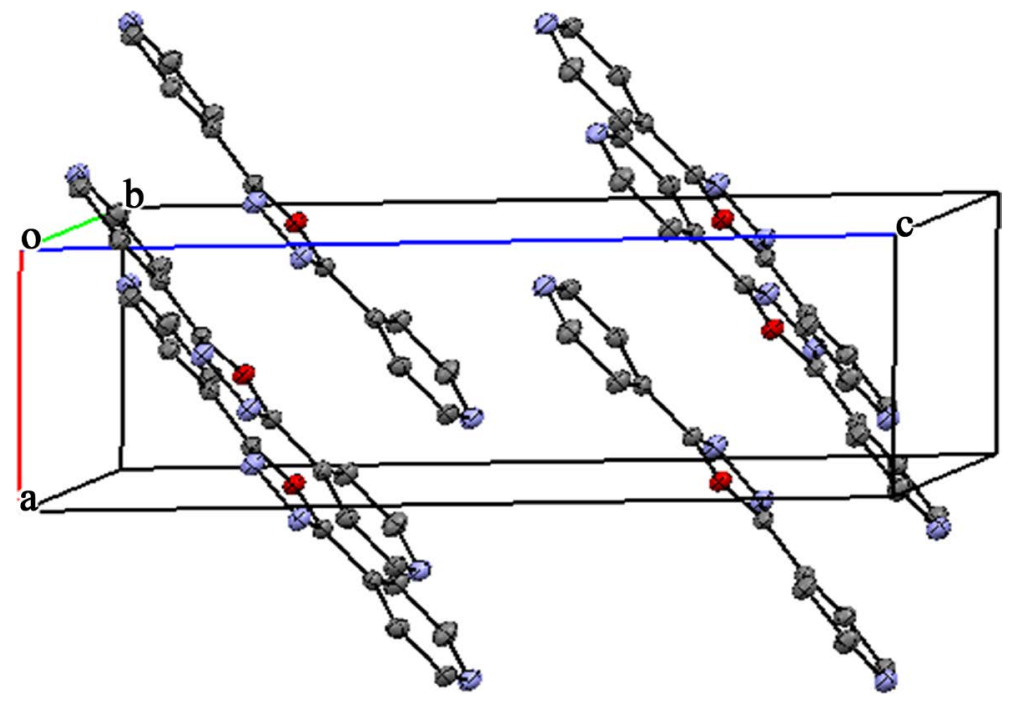

Figure 4. Molecular packing diagram of precursor 2 viewed along the $b$ axis and thermal ellipsoids are drawn on $50 \%$ probability level.

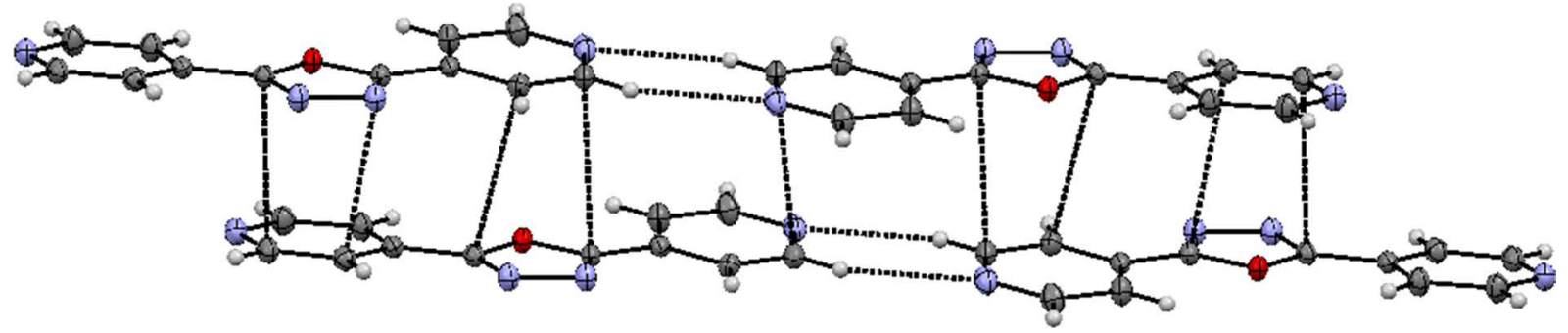

Figure 5. Molecular short contacts of diagram precursor 2 and thermal ellipsoids are drawn on 50\% probability level.

Table 2. Intermolecular short contacts of precursor 2.

\begin{tabular}{cccc}
\hline Short contact & Length (d) $\AA$ & Short contact & Length (d) \\
\hline C4 $\cdots \mathrm{C} 5$ & 3.322 & $\mathrm{C} 6 \cdots \mathrm{C} 6$ & 3.376 \\
C6 $\cdots \mathrm{C} 4$ & 3.288 & $\mathrm{~N} 1 \cdots \mathrm{H} 6$ & 2.585 \\
\hline
\end{tabular}

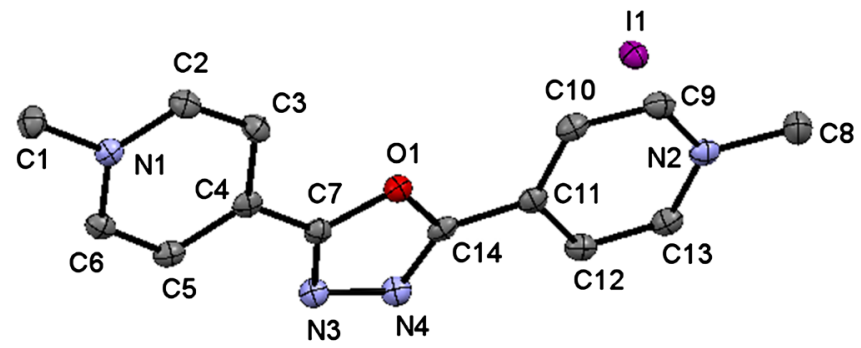

$\Phi 12$

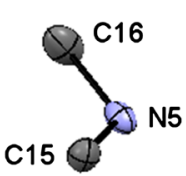

Figure 6. Molecular structure of molecule 4 viewed along the $b$ axis and thernal ellipsoids are drawn on $50 \%$ probability level. Hydrogen atoms are omitted for clarity. 
anions. In the crystal structure, we found dimethylammonium cation, which may have formed as a result of the reaction between dimethyl formamide (DMF) reaction solvent and iodomethane reagent during the reaction (step 4), co-crystallized along with the molecule 4 . The shape of molecule 4 seems to be planar, but it is a strained one. The dihedral angels between the planes of two pyridinium and oxadiazole rings are $5^{\circ}$ and $8^{\circ}$.

The crystal packing of the molecule 4 is shown in Figure 7. Intermolecular short contacts are listed in Table 3 and intermolecular short contacts are depicted in Figure 8. In between the molecule there exists $\mathrm{C}-\mathrm{H} \cdots \mathrm{I}$ short contacts. In between the layers, the molecules are packed and stabilized by C...C, C...I, N...I, N...H and H...I short contacts generated three-dimensional geometry. Dimethylammonium cation bound in the crystal system via $\mathrm{N}-\mathrm{H} \cdots \mathrm{I}$ and $\mathrm{C}-\mathrm{H} \cdots \mathrm{I}$ short contacts.

\section{Conclusion}

In conclusion, we reported the design, synthesis, molecular structure and photophysical properties of new viologen fluorophore molecule 4 and its precursor

2. The crystal structure of molecule 4 is quite interesting due to the presence of

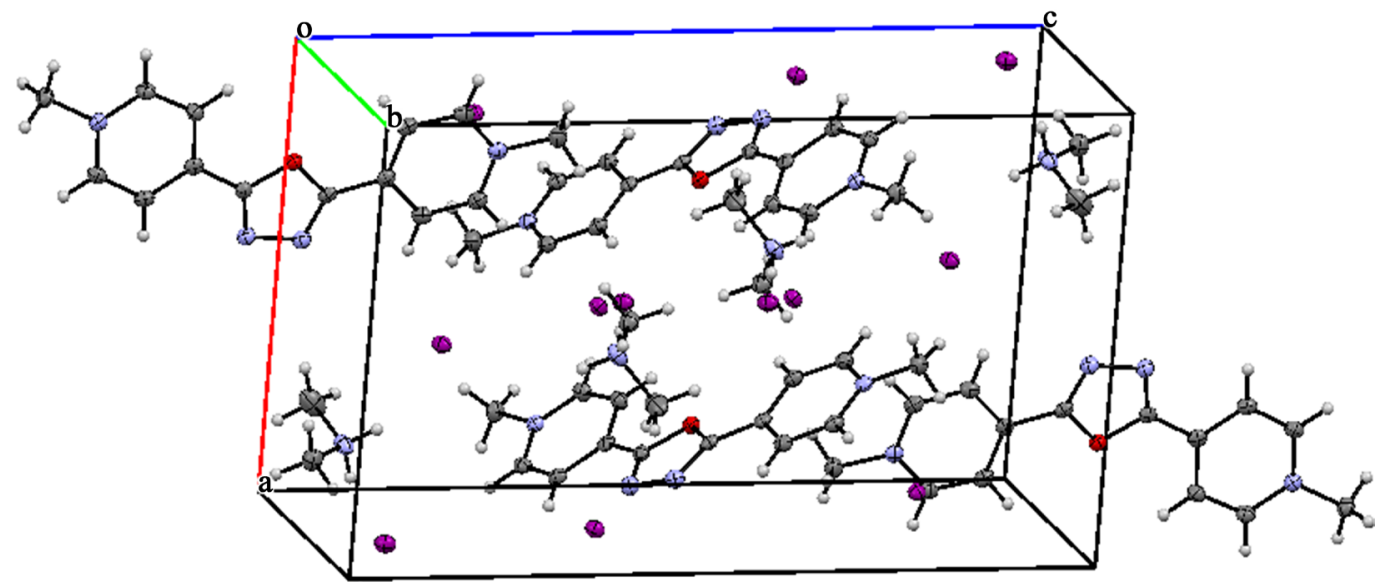

Figure 7. Molecular packing diagram of molecule 4 viewed along the $b$ axis and thermal ellipsoids are drawn on $50 \%$ probability level.

Table 3. Intermolecular short contacts of molecule 4 .

\begin{tabular}{|c|c|c|c|}
\hline Short contact & Length (d) $\AA$ & Short contact & Length (d) \\
\hline $\mathrm{C} 5 \cdots \mathrm{C} 12$ & 3.358 & H9...I2 & 2.923 \\
\hline N4‥H16B & 2.606 & $\mathrm{H} 1 \mathrm{C} \cdots \mathrm{I} 3$ & 3.179 \\
\hline $\mathrm{C} 13 \cdots \mathrm{I} 1$ & 3.58 & H15B $\cdots I 1$ & 3.053 \\
\hline C9...I1 & 3.631 & 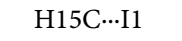 & 3.164 \\
\hline H1A $\cdots$ I1 & 3.099 & N5 $\cdots$ I2 & 3.444 \\
\hline $\mathrm{H} 2 \cdots \mathrm{I} 1$ & 2.955 & $\mathrm{H} 17 \mathrm{~A} \cdots \mathrm{I} 2$ & 2.625 \\
\hline H5 $\cdots \mathrm{I} 1$ & 3.096 & 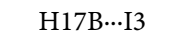 & 3.385 \\
\hline $\mathrm{H} 12 \cdots \mathrm{I} 2$ & 3.093 & & \\
\hline
\end{tabular}




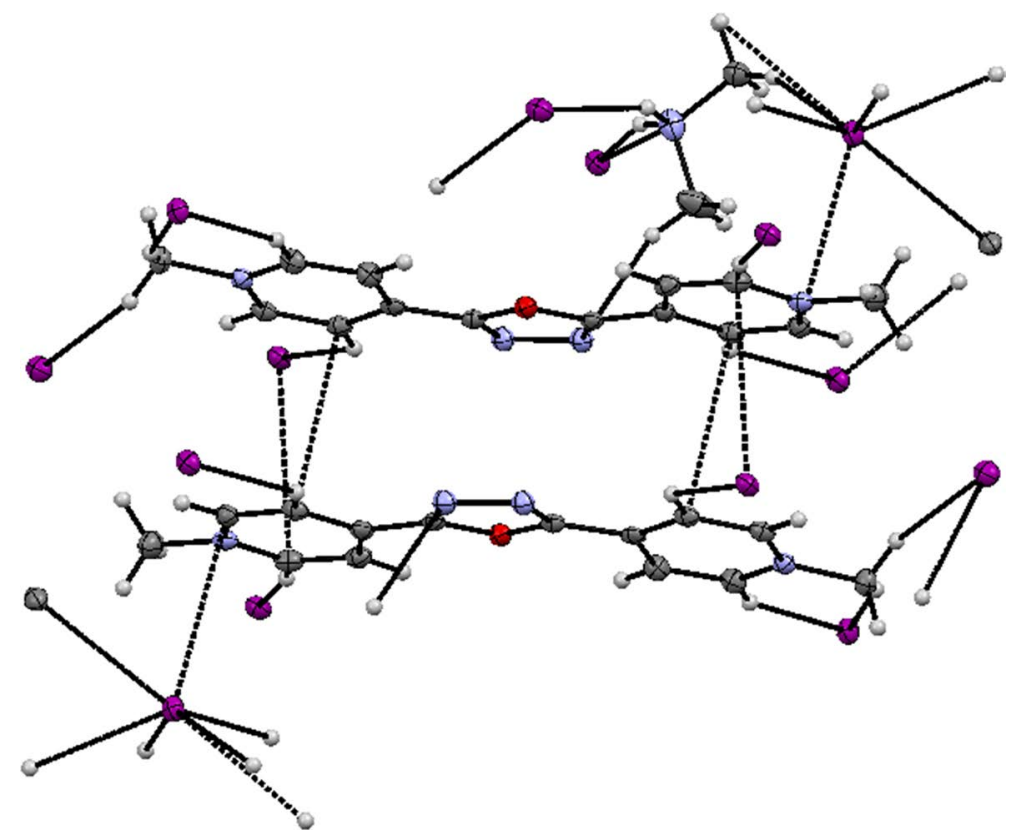

Figure 8. Molecular short contacts diagram of molecule 4 and thermal ellipsoids are drawn on $50 \%$ probability level.

one dimethylammonium cation and three iodide anions in molecular structure. The viologen molecule 4 exhibited strong and sharp fluorescence emission between 390 - $410 \mathrm{~nm}$, as a result fluorescence quantum yield may be improved, which is one of the prerequisites to find wide applications of viologen compounds, which may make these materials attractive for application in electrochromic devices, electron transfer sensing devices. We hope this research may help in understanding the insights of structure add property relationship of oxadiazole extended viologen compounds, which may help in designing novel viologen compounds with high quantum efficiency.

\section{Acknowledgements}

We are grateful to the Center for Instrumental Analysis, Kyushu Institute of Technology (KITCIA) for ${ }^{1} \mathrm{HNMR}$ spectra and X-ray analysis.

\section{Conflicts of Interest}

The authors declare no conflicts of interest regarding the publication of this paper.

\section{References}

[1] Striepe, L. and Baumgartner, T. (2017) Viologens and Their Application as Functional Materials. Chemistry-A European Journal, 23, 16924-16940. https://doi.org/10.1002/chem.201703348

[2] Binnemans, K. (2005) Ionic Liquid Crystals. Chemical Reviews, 105, 4148-4204. https://doi.org/10.1021/cr0400919

[3] Fernandez, A.A and Kouwer, P.H.J. (2016) Key Developments in Ionic Liquid 
Crystals. International Journal of Molecular Sciences, 17, 731. https://doi.org/10.3390/ijms17050731

[4] Goossens, K., Lava, K., Bielawski, C.W. and Binnemans, K. (2016) Ionic Liquid Crystals: Versatile Materials. Chemical Reviews, 116, 4643-4807. https://doi.org/10.1021/cr400334b

[5] Kato, T., Yoshio, M., Ichikawa, T., Soberats, B., Ohno, H. and Funahashi, M. (2017) Transport of Ions and Electrons in Nanostructured Liquid Crystals. Nature Reviews Materials, 2, Article No. 17001. https://doi.org/10.1038/natrevmats.2017.1 https://www.nature.com/articles/natrevmats20171?proof $=\mathrm{t}$

[6] Monk, P.M.S. (1998) The Viologens Physiochemical Properties, Synthesis and Applications of the Salts of 4,4-Bipyridine. Wiley, New York, 1-311.

[7] Rigby, C.R., Han, H., Bhowmik, P.K., Bahari, M., Harb, J.N., Lewis, R.S. and Watt, G.D. (2018) Soluble Viologen Polymers as Carbohydrate Oxidation Catalysts for Alkaline Carbohydrate Fuel Cells. Journal of Electroanalytical Chemistry, 823, 416421. https://doi.org/10.1016/j.jelechem.2018.05.016

[8] Frolova, L.A., Troshin, P.A., Susarova, D.K., Kulikov, A.V., Sanina, N.A. and Aldoshin, S.M. (2015) Photoswitchable Organic Field-Effect Transistors and Memory Elements Comprising an Interfacial Photochromic Layer. Chemical Communications, 51, 6130-6132. https://doi.org/10.1039/C5CC00711A

[9] Camden, D., Hu, B., Moss, J., Liu, X., Luo, J., Sun, Y. and Liu, T.L. (2017) Designer Two-Electron Storage Viologen Anolyte Materials for Neutral Aqueous Organic Redox Flow Batteries. Chem, 3, 961-978. https://doi.org/10.1016/j.chempr.2017.11.001

[10] Chen, C., Zhang, S., Zhu, Y.Z., Qian, Y., Niu, Z., Ye, J. and Zhao, Y. and Zhang, X. (2018) Pyridyl Group Design in Viologens for Anolyte Materials in Organic Redox Flow Batteries. RSC Advances, 8, 18762-18770. https://doi.org/10.1039/C8RA02641F

[11] Roy, S. and Rhim, J.-W. (2018) Erratum to "Probing the Binding Interaction of Lysozyme-Viologen Herbicide”. Journal of Molecular Structure, 1171, 1-8. https://doi.org/10.1016/j.molstruc.2018.05.096

[12] Wang, R.-T., Lee, G.-H. and Lai, C.K. (2018) Anion-Induced Ionic Liquid Crystals of Diphenylviologens. Journal of Materials Chemistry C, 6, 9430-9444. https://doi.org/10.1039/C8TC03090A

[13] Bhowmik, P.K., Chang, A., Kim, J., Dizon, E.J., Principe, R.C.J. and Han, H. (2019) Thermotropic Liquid-Crystalline Properties of Viologens Containing 4-n-alkylbenzenesulfonates. Crystals, 9, 77. https://doi.org/10.3390/cryst9020077

[14] Woodward, A.N., Kolesar, J.M., Hall, S.R., Saleh, N.-A., Jones, D.S. and Walter, M.G. (2017) Thiazolothiazole Fluorophores Exhibiting Strong Fluorescence and Viologen-Like Reversible Electrochromism. Journal of the American Chemical Society, 139, 8467-8473. https://doi.org/10.1021/jacs.7b01005

[15] Higashi, T. and Sagara, T. (2013) Diphenyl Viologen on an HOPG Electrode Surface: Less Sharp Redox Wave than Dibenzyl Viologen. Langmuir, 29, 11516-11524. https://doi.org/10.1021/la401606v

[16] Nanasawa, M., Miwa, M., Hirai, M. and Kuwabara, T. (2000) Synthesis of Viologens with Extended $\pi$-Conjugation and Their Photochromic Behavior on Near-IR Absorption. The Journal of Organic Chemistry, 65, 593-595. https://doi.org/10.1021/j0990911v

[17] Veltri, L., Cavallo, G., Beneduci, A., Metrangolo, P., Corrente, G.A., Ursini, M., Romeo, R., Terraneo, G.T. and Gabriele, B. (2019) Synthesis and Thermotropic 
Properties of New Green Electrochromic Ionic Liquid Crystals. New Journal of Chemistry, 43, 18285-18293. https://doi.org/10.1039/C9NJ03303C

[18] Bockman, T.M. and Kochi, J.K. (1990) Isolation and Oxidation-Reduction of Methylviologen Cation Radicals. Novel Disproportionation in Charge-Transfer Salts by X-Ray Crystallography. The Journal of Organic Chemistry, 55, 4127-4135. https://doi.org/10.1021/jo00300a033

[19] Chen, Z.W., Lu, G., Li, P.-X., Lin, R.-G., Cai, L.-Z., Wang, M.-S. and Guo, G.-C. (2014) Influence of Supramolecular Interactions on Electron-Transfer Photochromism of the Crystalline Adducts of 4,4'-Bipyridine and Carboxylic Acids. Crystal Growth \& Design, 14, 2527-2531. https://doi.org/10.1021/cg500239p

[20] Tanaka, R. and Matsushita, N. (2017) A Charge-Transfer Salt Composed of Methyl Viologen and hexacyanidoferrate(II). Acta Crystallographica Section C Structural Chemistry, 73, 476-480. https://doi.org/10.1107/S2053229617007616

[21] (2009) APEX2 Version 2009.9. Bruker AXS Inc., Tokyo.

[22] (2009) SAINT Version 7.68A. Bruker AXS Inc., Tokyo.

[23] Sheldrick, G.M.A. (2008) Short History of SHELX. Acta Crystallographica Section $A, 64,112-122$. https://doi.org/10.1107/S0108767307043930 